\title{
Influence of beta adrenergic blockade on effects of physical training in patients with ischaemic heart disease
}

\author{
L VANHEES, R FAGARD, A AMERY
}

From the Hypertension and Cardiovascular Rehabilitation Unit, Department of Pathophysiology, University of Leuven (KU Leuven), Leuven, Belgium

SUMMARY Reduction in heart rate during submaximal exercise is often used to judge the progress of patients with ischaemic heart disease in the course of a physical training programme. Some patients, however, are treated with beta adrenergic blocking drugs and it remains controversial if chronic beta blockade influences the effects of training and if heart rate remains a useful guide in the evaluation of the state of training of these patients.

Male postinfarction patients, 15 treated with and 15 without beta blockers, were trained for three months, three times a week. Cardiorespiratory results from uninterrupted incremental exercise tests before and after training were compared. In each subgroup, the heart rate and systolic blood pressure were significantly reduced. For heart rate the decrease after training became more pronounced with increasing work load and the overall reduction was significantly less in the beta blocker group compared with the patients not treated with beta blockers. For systolic blood pressure the training-induced reductions were more pronounced in the patients on beta blockers.

The increase of peak oxygen uptake was similar in the patients with and without beta blockers, namely $36 \%$ and $34.5 \%$. At submaximal exercise carbon dioxide output, pulmonary minute ventilation, and the respiratory exchange ratio were lower after training, and these effects of training were similar whether or not the patients were on beta blockers.

The study shows that the usual effects of training are observed in patients on beta blockers, and that heart rate remains a useful guide to their evaluation throughout a physical training programme.

The cardiorespiratory effects of physical training have been intensively studied in normal subjects and include increases in both maximal oxygen uptake and maximal pulmonary ventilation, an increase in the anaerobic threshold, and reductions in heart rate and possibly blood pressure at rest and at submaximal work. ${ }^{1}$

Physical training has been used in the rehabilitation of patients with ischaemic heart disease, with roughly similar cardiorespiratory effects. ${ }^{23}$ The reduction in heart rate during submaximal work is often used to judge the progress of the patient during the programme. Some of these patients, however, are taking beta adrenergic blocking drugs for hypertension, angina, or other disorders. It remains controversial if chronic beta blockade influences the effects of train-

Accepted for publication 2 March 1982 ing and if heart rate remains a useful guide in the evaluation of the state of training of these patients. ${ }^{45}$

Therefore, in the present study, we compare the cardiorespiratory effects of training in two groups of patients with ischaemic heart disease: one group treated with beta blockers and the other without.

\section{Subjects and methods}

\section{(1) SUBJECTS}

The study was performed on male patients who were referred to the cardiac rehabilitation unit eight or more weeks after they had suffered from a myocardial infarction. Thirty patients were studied and they all fulfilled the following criteria: no alteration of medication during the training programme, nor for at least six weeks before the pretraining test; no limitation by angina pectoris during pre- and post-training evalua- 
tion and attainment of a work level of at least 110 Watts at the pre-training test. Their characteristics are given in Table 1. Fifteen patients were on beta blockers, and their characteristics were similar to those of the patients without these drugs. The doses of beta blocking drugs are given in Table 2 .

\section{(2) TRAINING PROGRAMME}

The physical training programme was designed so that the patients would exercise indoors for three months, three days a week for a total duration of 75 minutes, rest included, for each exercise session. Each session consisted of: cycling for 10 minutes, rowing twice for two and a half minutes, running twice for four minutes, and callisthenics twice for 15 minutes. The intensity of the exercise was adapted to 60 to $80 \%$ of the measured maximal capacity for each patient. An exercise leader and a physician supervised all exercise sessions.

\section{(3) TESTING PROCEDURES}

\section{(a) General outline}

Testing before and after training was performed using uninterrupted graded exercise on an electromagnetically braked cycle ergometer (Elema Schönander EMT 369), in an air-conditioned laboratory (temperature 18 to $22^{\circ} \mathrm{C}$, humidity 40 to $60 \%$ ), according to an identical procedure. Each subject was tested at approximately the same time of the day before and after training, mostly in the afternoon. Observations were made after 10 minutes sitting on the bicycle (RS) and at several work levels: the patients first exercised at 20 Watts for four minutes and then the exercise rate was increased by 30 Watts every four minutes. All the patients were allowed to perform a symptom limited graded exercise test, that is they determined the point of interruption themselves from their subjective feelings (exhaustion, dyspnoea, pain, or tiredness in the legs). It was not felt acceptable to encourage them any further in view of their ischaemic heart disease. Their final values are indicated as "peak" values.

\section{(b) Cardiorespiratory variables}

The patient's electrocardiogram was monitored via a high persistence oscilloscope, and heart rate was calculated continuously. Systolic blood pressure was measured with a standard mercury sphygmomanometer. The product of heart rate and systolic blood pressure (rate pressure product) was calculated.

\section{(c) Respiratory variables}

Pulmonary minute ventilation $\left(V_{E}\right)$ was measured with a pneumotachograph and expressed in $1 / \mathrm{min}$, BTPS conditions (body temperature, barometric pressure, saturated with water vapour), oxygen con-
Table 1 Characteristics of patients

\begin{tabular}{|c|c|c|}
\hline & $\begin{array}{l}\text { Patients treated } \\
\text { with } \\
\text { beta blockers }\end{array}$ & $\begin{array}{l}\text { Patients } \\
\text { without } \\
\text { beta blockers }\end{array}$ \\
\hline $\begin{array}{l}\text { No. } \\
\text { Age }(\mathrm{y})^{\star} \\
\text { Weight }(\mathrm{kg})^{\star} \\
\text { Height }(\mathrm{m})^{\star} \\
\text { Body surface area }\left(\mathrm{m}^{2}\right)^{\star} \\
\text { Time between infarction and }\end{array}$ & $\begin{array}{l}15 \\
49.00 \pm 2.2 \\
73.00 \pm 1.5 \\
1.74 \pm 0.01 \\
1.87 \pm 0.03\end{array}$ & $\begin{array}{l}15 \\
50.50 \pm 1.4 \\
70.10 \pm 2.1 \\
1.72 \pm 0.02 \\
1.83 \pm 0.03\end{array}$ \\
\hline $\begin{array}{l}\text { onset of training }(w k)^{\star} \\
\text { Duration of training (wk) } \\
\text { Frequency of training per week }\end{array}$ & $\begin{array}{r}27 \cdot 60 \pm 6.3 \\
13 \cdot 90 \pm 0.5 \\
\star \quad 2.51 \pm 0.1\end{array}$ & $\begin{array}{r}15 \cdot 20 \pm 3 \cdot 5 \\
13 \cdot 60 \pm 0.4 \\
2 \cdot 41 \pm 0.1\end{array}$ \\
\hline
\end{tabular}

*The data are means $\pm S E$.

There are no significant differences between the groups for any of the variables.

centration by a paramagnetic oxygen analyser, and carbon dioxide concentration by an infrared carbon dioxide analyser (Siregnost FD 80, Siemens). Oxygen uptake $\left(\dot{\mathrm{VO}}_{2}\right)$ and carbon dioxide output $\left(\mathrm{V}^{2} \mathrm{O}_{2}\right)$, expressed in $1 / \mathrm{min}$, were continuously calculated and reduced to STPD conditions (standard temperature and pressure, dry). The respiratory exchange ratio $\left(\mathrm{R}=\mathrm{V} \mathrm{CO}_{2} / \mathrm{VO}_{2}\right)$ and the respiratory equivalent for oxygen $\left(\mathrm{RE}=\mathrm{V}_{\mathrm{E}} / \mathrm{VO}_{2}\right)$ were calculated. A definition of these variables is given in the "glossary on respiration and gas exchange". 6

\section{(4) ANALYSIS OF DATA}

The data were analysed separately for the patients treated with and those without beta blockers, at rest in the sitting position, at the work rates of $20,50,80$, and 110 Watts which were performed by all, and at the final work rate.

For statistical analysis, observations during the last five minutes in the sitting position were used, and during exercise the data of the last minute at each

Table 2 Details of treatment in patients

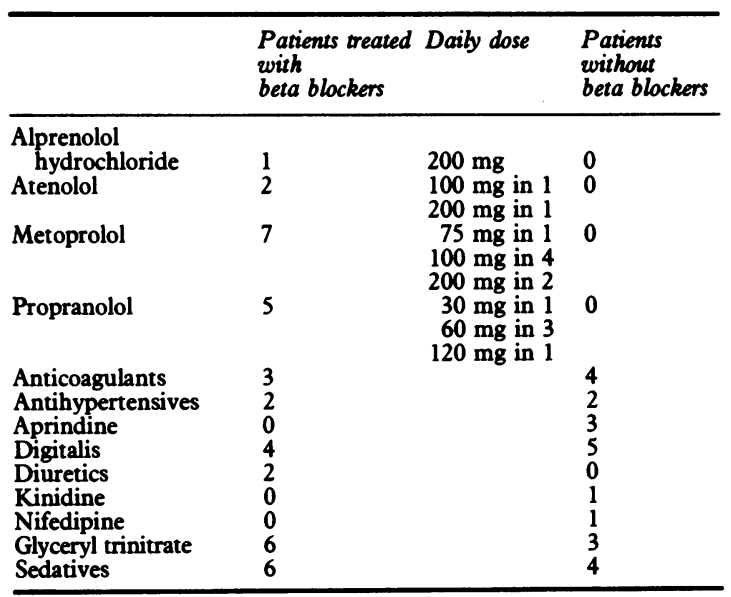


exercise level. Unpaired $t$ tests were used to evaluate possible differences between both groups of patients, paired $t$ tests, and analysis of variance to compare preand post-training observations. ${ }^{7}$ The dispersion of the data is given by standard error of mean.

\section{Results}

\section{(1) OBSERVATIONS AT REST AND SUBMAXIMAL EXERCISE}

(a) Cardiovascular variables

Pre-training heart rate was lower in the patients on beta blockers when compared with those without such treatment as indicated by the lower heart rates at RS-11 beats/min $(p<0.05)$, at $20 \mathrm{~W}-10$ beats $/ \mathrm{min}$ $(\mathrm{p}<0.05)$, at $50 \mathrm{~W}-10$ beats $/ \mathrm{min}(\mathrm{p}<0.05)$, at $80 \mathrm{~W}-12$ beats/min $(p<0.01)$, and at $110 \mathrm{~W}-16$ beats/min $(p<0.001)$ (Fig. 1). Pre-training systolic blood pressure was not significantly different in the treatment groups.

Training reduced both heart rate and blood pressure. Fig. 1 summarises the absolute levels of heart rate. In Fig. 2 the changes from the pre-training test

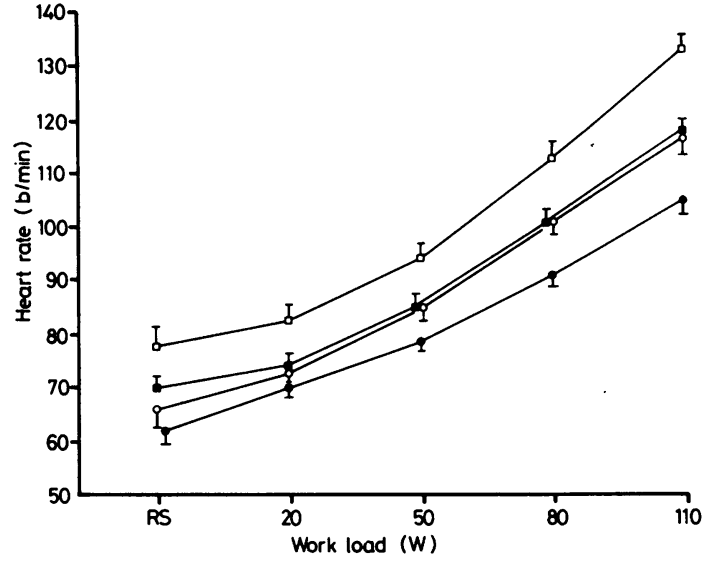

Fig. 1 Heart rate before (open signs) and after training (closed signs) in patients treated with beta blockers (circles) and in those without beta blockers (squares) at rest in the sitting position (RS) and at $20 \mathrm{~W}, 50 \mathrm{~W}, 80 \mathrm{~W}$, and $110 \mathrm{~W}$. Values are means $\pm S E$.

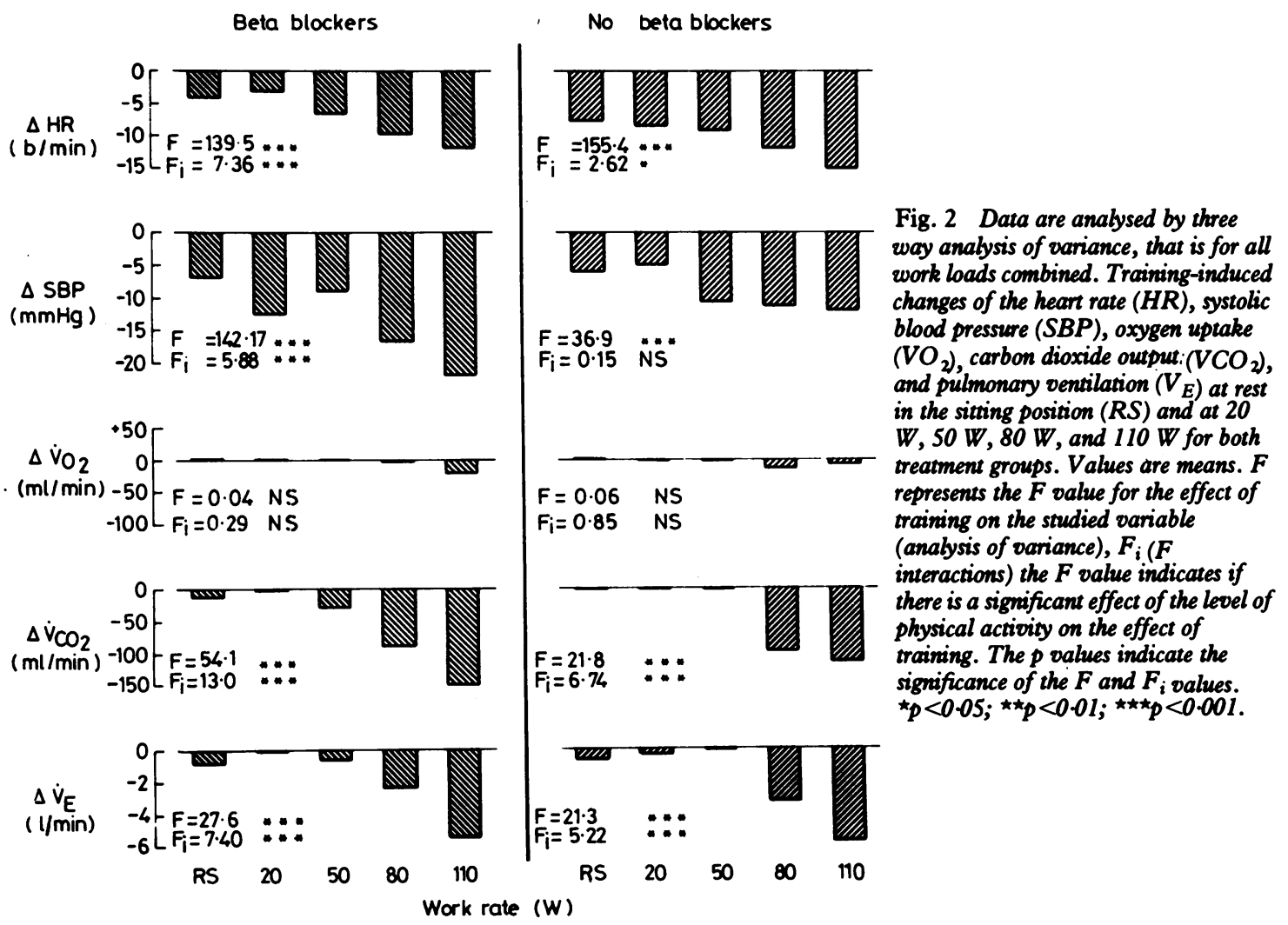


Table 3 Comparison of peak data of cardiorespiratory variables at symptom limited maximal exercise before and afier training for patients treated with and without beta blockers (values are means $\pm S E$ )

\begin{tabular}{|c|c|c|c|c|}
\hline & \multicolumn{2}{|c|}{ Patients treated with beta blockers $(n=15)$} & \multicolumn{2}{|c|}{ Patients treated without beta blockers $(n=15)$} \\
\hline & Before training & After training & Before training & After training \\
\hline $\begin{array}{l}\text { HR (beats } / \mathrm{min}) \\
\text { SBP }(\mathrm{mmH}) \\
\text { RPP (beats } / \mathrm{min} \times \mathrm{mmH}) \\
\text { VO }(\mathrm{ml} / \mathrm{min}) \\
\mathrm{VCO}_{2}(\mathrm{ml} / \mathrm{min}) \\
\mathbf{V}_{\mathbf{E}}(\mathbf{l} / \mathrm{min}) \\
\mathbf{R} \\
\text { RE }\end{array}$ & $\begin{array}{c}124 \pm 3.6 \\
186 \pm 6.3 \\
23106 \pm 1260 \\
1627 \pm 59 \\
1721 \pm 78 \\
50.4 \pm 2.1 \\
1.04 \pm 0.03 \\
29.6 \pm 1.5\end{array}$ & $\begin{array}{c}135 \pm 3 \cdot 5^{\star \star} \\
190 \pm 6.8 \\
25530 \pm 1179 \star \\
2213 \pm 89 \star \star \star \\
2403 \pm 131 \star \star \star \\
70.4 \pm 3.4^{\star \star \star} \\
1.08 \pm 0.02 \\
31.9 \pm 1.0\end{array}$ & $\begin{array}{c}137 \pm 4.3 \\
175 \pm 9.2 \\
23595 \pm 1513 \\
1521 \pm 57 \\
1637 \pm 61 \\
50.5 \pm 1.9 \\
1.08 \pm 0.01 \\
33.8 \pm 1.6\end{array}$ & $\begin{array}{c}148 \pm 4 \cdot 3^{\star} \\
189 \pm 6 \cdot 8^{\star} \\
27508 \pm 1375^{\star} \\
2044 \pm 60^{\star \star \star} \\
2232 \pm 83^{\star \star \star} \\
70 \cdot 9 \pm 3 \cdot 6 \star \star \star \\
1 \cdot 11 \pm 0.02 \\
35 \cdot 2 \pm 1 \cdot 4\end{array}$ \\
\hline
\end{tabular}

P values are given for the comparison of pre- and post-training values within each group: ${ }^{\star} p<0.05 ;{ }^{\star \star} p<0.01 ;{ }^{\star \star \star} p<0.001$.

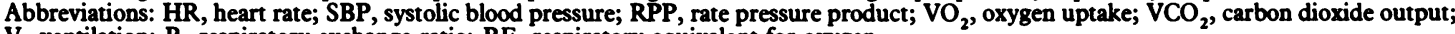
$V_{E}$ ventilation; $R$, respiratory exchange ratio; $R E$, respiratory equivalent for oxygen.

to the post-training evaluation for heart rate and systolic blood pressure, at rest in the sitting position and at $20,50,80$, and $110 \mathrm{~W}$ are illustrated for both subgroups. For resting and exercise data $(20 \mathrm{~W}$ to $110 \mathrm{~W})$ combined, the $95 \%$ confidence limits of the traininginduced reductions in heart rate and in systolic blood pressure were, respectively, 6.2 to 8.6 beats/min and 11.4 to $15.8 \mathrm{mmHg}$ for the patients on beta blockers and 8.8 to 12.1 beats/min and 6 to $11.5 \mathrm{mmHg}$ for those without such treatment. These changes were significant $(p<0.001$ for all) in each subgroup, when three-way analysis of variance was applied, taking (1) resting and exercise conditions (levels of physical activity), (2) subjects, and (3) training into consideration. In general the effects of training appear to be more pronounced with increasing levels of physical activity. When the two subgroups were compared it was found that the training-induced changes of heart rate in the beta blocked group were significantly $(p<0.01)$ less than in the group without beta blockers. The changes of systolic blood pressure, however, were more pronounced $(p<0.05)$ in the beta blocked group.

\section{(b) Respiratory variables}

Fig. 2 also illustrates the differences for oxygen uptake, carbon dioxide output, and pulmonary ventilation from pre- to post-training for the two subgroups. The observations were similar and statistically not different in patients with and patients without beta blockers. Whereas the oxygen uptake was not affected by training, carbon dioxide output and pulmonary ventilation remained unchanged at 20 and $50 \mathrm{~W}$, but decreased at 80 and $110 \mathrm{~W}$, reflected by the significant interactions between the levels of physical activity and the training effect (all significant at $\mathrm{p}<0.001)$. The respiratory exchange ratio was significantly reduced by $7.5 \%$ at $80 \mathrm{~W}$ and by $8.8 \%$ at $110 \mathrm{~W}$ for the group receiving beta blockers and by $6.2 \%$ at $80 \mathrm{~W}$ and $7.7 \%$ at $110 \mathrm{~W}$ in the group not on beta blockers; no significant differences were observed at the other work rates.

\section{(2) OBSERVATIONS AT SYMPTOM LIMITED} MAXIMAL EXERCISE

Table 3 summarises the peak data for the two treatment groups. Heart rate, rate pressure product, oxygen uptake, carbon dioxide output, and pulmonary ventilation were significantly increased in both subgroups after training. The increase of systolic blood pressure was only significant in patients without beta blockers. The respiratory exchange ratio and the respiratory equivalent for oxygen were not different before and after training. Overall the results were similar and not significantly different for the patients with and those without beta blockers.

\section{Discussion}

\section{(1) EFFECTS OF TRAINING}

The data demonstrate the effectiveness of the training programme and are in agreement with previous reports on physical training in normal subjects and in cardiac patients.

At rest and at submaximal levels of exercise, heart rate, systolic blood pressure, and the rate pressure product were reduced, which is in agreement with previous reports, ${ }^{8-13}$ except for systolic blood pressure in some studies. ${ }^{1415}$ In both groups the patients were able to support a higher level of cardiac work since the peak values of these variables were higher after training compared with before training, whereas the respiratory exchange ratio and the respiratory equivalent for oxygen were not statistically different. After training the pre-training peak values of the rate pressure product were reached at a $21 \%$ higher oxygen uptake. This suggests that after training, a higher work rate can be attained with a similar myocardial oxygen consumption, since the product of 
heart rate and systolic blood pressure is well correlated with the oxygen uptake of the heart. ${ }^{16}$

Total body oxygen uptake at submaximal work is not affected by training, in agreement with an unchanged mechanical efficiency. ${ }^{2317}$ From $80 \mathrm{~W}$ on, however, carbon dioxide output, pulmonary ventilation, and the respiratory exchange ratio were lower after training, suggesting a reduced contribution of anaerobic metabolism to the energy production. ${ }^{18}$ Peak oxygen uptake increased significantly after training by, on average, $35 \%$ in both groups. Since the subjects could attain a similar respiratory exchange ratio, carbon dioxide output and consequently pulmonary ventilation attained higher values, a well recognised effect of training. ${ }^{15}$

(2) EFFECTS OF BETA ADRENERGIC BLOCKADE Fifteen patients were on treatment with beta adrenergic blocking agents for at least six weeks before the study. Since heart rate was not measured during a similar exercise test before the drug was started, the degree of beta blockade cannot be ascertained; however, the pretraining heart rate of these patients in the sitting position at rest, which averaged $66 \mathrm{beats} / \mathrm{min}$, is $15 \%$ lower than the heart rate of the patients who did not receive beta blockers. Overall these data show that training effects can be achieved in patients on beta blockers. This indicates that the intensity of exercise during the training sessions is adequate. It has been suggested that beta blockers limit exercise capacity. ${ }^{19}$ Our data cannot answer this problem but at least a sufficient degree of exercise intensity can be achieved to obtain training effects.

\section{(a) Respiratory variables}

Beta adrenoceptor blockade did not influence the effects of training on the respiratory variables which is in accordance with Obma et al. ${ }^{5}$ but not with Malmborg et al. ${ }^{4}$ The number of patients in the latter study was small, however, and the training intensity low. In the present study the effects of training on aerobic and anaerobic metabolism were similar whether or not the patients were treated with beta blockers. This is in accord with studies of Wasserman et al. ${ }^{20}$ who showed that neurogenic factors did not play an important role in the ventilatory control during exercise.

\section{(b) Cardiovascular variables}

Endurance training reduced heart rate, which is considered the result of altered sympatheticparasympathetic tone. Parasympathetic blocking agents such as atropine have been shown to increase the pre- and post-training heart rates to a similar extent at rest, ${ }^{21}$ but the increase at submaximal exercise was greater after training; these findings suggest an increased parasympathetic tone in response to training, at least during exercise. An augmented vagal tone was also shown in trained rats. ${ }^{22} 23$ On the other hand, the reduction of heart rate by the beta adrenoceptor blocker propranolol was less pronounced after than before training, suggesting reduced sympathetic tone after training, ${ }^{21}$ which is in accordance with the observed decrease of plasma noradrenaline levels. ${ }^{24} 25$

In the present study heart rate decreased significantly after training in patients on chronic treatment with beta adrenoceptor blockers, and the decreases of heart rate were close to, though significantly smaller than those of patients without such treatment. Since beta adrenoceptors were blocked throughout the study, though probably incompletely in a clinical setting, an increase of the parasympathetic tone is a more likely explanation for the observed exercise-induced bradycardia. The many other mechanisms which have been postulated such as ventricular hypertrophy, decreased sensitivity of cardiac adrenergic receptors, and intrinsic changes of the sinus node, can, of course, not be excluded.

The study thus shows that beta blockade does not influence the effects of physical training on various respiratory variables and that heart rate remains a useful guide for the evaluation of patients with ischaemic heart disease on treatment with beta adrenoceptor blockers throughout a physical training programme, provided that the degree of beta blockade remains unchanged.

This study was partly supported by a grant from the Belgian IWONL.

\section{References}

1 Clausen JP. Circulatory adjustments to dynamic exercise and effect of physical training in normal subjects and in patients with coronary artery disease. Prog Cardiovasc Dis 1976; 18: 459-95.

2 Detry JMR. Exercise testing and training in coronary heart disease. Leiden: HE Stenfert-Kroese BV, 1973: 51-61.

3 Kellermann JJ. Rehabilitation of patients with coronary heart disease. Prog Cardiovasc Dis 1975; 17: 303-29.

4 Malmborg R, Isaccson S, Kallivroussis G. The effect of beta blockade and/or physical training in patients with angina pectoris. Current Therapeutic Research 1974; 16: 171-83.

5 Obma RT, Wilson PK, Goebel ME, Campbell DE. Effect of a conditioning program in patients taking propranolol for angina pectoris. Cardiology 1979; 64: 36571.

6 International Union of Physiological Sciences Glossary Committee. Glossary on respiration and gas exchange. $\mathcal{f}$ Appl Physiol 1973; 34: 549-58.

7 Armitage P. Statistical methods in medical research. Oxford \& Edinburgh: Blackwell Scientific Publications, 1971: 189-207. 
8 Varnauskas E, Bergman H, Houk P, Bjørntorp P. Haemodynamic effects of physical training in coronary patients. Lancet 1966; ii: 8-12.

9 Sanne H. Exercise tolerance and physical training of non-selected patients after myocardial infarction. Acta Med Scand 1973; suppl 551: 7-110.

10 Rousseau MF, Brasseur LA, Detry JM. Hemodynamic determinants of maximal oxygen uptake in patients with healed myocardial infarction. Influence of physical training. Circulation 1973; 48: 943-9.

11 Hellerstein HK. Exercise therapy in coronary disease. Bull NY Acad Med 1968; 44: 1028-47.

12 Hartley LH, Grimby G, Kilbom A, et al. Physical training in sedentary middle-aged and older men. III. Cardiac output and gas exchange at submaximal and maximal exercise. Scand 7 Clin Lab Invest 1969; 24: 335-44.

13 Bjernulf A. Haemodynamic aspects of physical training after myocardial infarction. Acta Med Scand 1973; suppl 548: $1-50$.

14 Frick MH, Konttinen A, Sarajas HS. Effects of physical training on circulation at rest and during exercise. Am $\mathcal{J}$ Cardiol 1963; 12: 142-7.

15 Ekblom B, Astrand PO, Saltin B, Stenberg J, Wallström B. Effect of training on circulatory response to exercise. f Appl Physiol 1968; 24: 518-28.

16 Kitamura K, Jorgensen CR, Gobel FL, Taylor HL, Wang Y. Hemodynamic correlates of myocardial oxygen consumption during upright exercise. $\mathcal{f}$ Appl Physiol 1972; 32: 516-22.

17 Scheuer J, Tipton CM. Cardiovascular adaptions to physical training. Annu Rev Physiol 1977; 39: 221-51.

18 Davis JA, Frank MH, Whipp BJ, Wasserman K.
Anaerobic threshold alterations caused by endurance training in middle-aged men. $\mathcal{F}$ Appl Physiol 1979; 46: $1039-46$.

19 Breckenridge A. Jogger's blockade. Br Med f 1982; 284: 532-3.

20 Wasserman K, Whipp BJ, Casaburi R, Golden M, Beaver WL. Ventilatory control during exercise in man. Bull Eur Physiopathol Respir 1979; 15: 27-51.

21 Ekblom B, Kilbom A, Soltysiak J. Physical training, bradycardia, and autonomic nervous system. Scand $\mathcal{F}$ Clin Lab Invest 1973; 32: 251-6.

22 Herrlich HC, Raab W, Gigee W. Influence of muscular training and of catecholamines on cardiac acetylcholine and cholinesterase. Arch Int Pharmacodyn 1960; 129: 201-15.

23 Tipton CM, Barnard RJ, Tcheng TK. Resting heart rate investigations with trained and non-trained hypophysectomized rats. F Appl Physiol 1969; 26: 585-8.

24 McCrimmon DR, Cunningham DA, Rechnitzer PA, Griffiths J. Effect of training on plasma catecholamines in postmyocardial infarction patients. Med Sci Sports 1976; 8: 152-6.

25 Winder WW, Hagberg JM, Hickson RC, Ehsani AA, McLane JA. Time course of sympathoadrenal adaptation to endurance exercise training in man. $\mathcal{F}$ Appl Physiol 1978; 45: 370-4.

Requests for reprints to Dr L Vanhees, Academisch Ziekenhuis Pellenberg, Cardiopulmonair Laboratorium, Inwendige Ziekten-Cardiologie, Weligerveld 1, B-3041 Pellenberg, Belgium. 